\title{
Research on the Innovation System of Cultivating Postgraduates for School-enterprise Cooperation
}

\author{
Zhang Cheng-he ${ }^{1}$ Li Cheng-shun ${ }^{2}$ Yuan Yu-zhen ${ }^{1^{*}}$ \\ ${ }^{1}$ Shandong University of Technology, Zibo 255049, China \\ ${ }^{2}$ Shandong Lu Yang Co., Ltd, Zibo 256100, China
}

\begin{abstract}
Through the study on the development course of school-enterprise cooperation mode, analysis of the present situation of the postgraduate education, this paper summarized the existing problems in the traditional education, and put forward the cultivation mode of the school-enterprise cooperation to train the postgraduates. Based on the analysis of the mode of school-enterprise cooperation, this paper proposes the implementation conditions and the research content of this mode.
\end{abstract}

Keywords: postgraduate education; schoolenterprise cooperation; cultivation mode

\section{Introduction}

School-enterprise Cooperation mode in cultivating postgraduates began in the USA[1]. American universities established various connection with industrial circle, which promoted the process of the industrialization of scientific research and made the overall strength and economic development of American universities a world leader.

In order to strengthen the linkages between higher education sector and industry, British[2] has set up a national education company. It also can enhance the scientific research turning in the direction of the actual production of higher education and improve the enthusiasm of teaching, to promote the technological progress and management level of industry. When companies apply to build the projects together with universities, teaching company's projects are effective, and these items must be derived from the actual production which really need to to be solved, can not be virtual. You can get Teaching Company Fund, once the project application are approved. Funding sum is usually required for the project cost $50 \%-70 \%$, while the parties involved in the project process must draft the project carefully and carry out. Thus, the teaching company makes universities join together with enterprises successfully through teaching projects. By the work of coordinators and regional system of regular meetings of the project tracking, inspection and coordination, the cooperation projects can be promoted continuously and develop smoothly.

Because of starting lately, our research was officially launched in 1992. The former State Economic and Trade Commission, Ministry of Education, Chinese Academy of Sciences jointly organized and implemented the "research joint development project" aiming to explore a technology suitable for China's economy closely integrated with the road, in order to accelerate the pace of industrialization of scientific and technological achievements[3-5]. It is also use of traditional industries, transforming by high technology, and gradually form a production, learning and research cooperation mechanism. After nearly two decades of construction and efforts, colleges or universities, as the main body of Combination achieved gratifying results, at the same time the creation of economic value and the resulting social significance are not to be underestimated. Research gives strong impetus to the reform of the education system under the Government's active lead. It not only promotes the transformation of scientific and technological achievements, but also accelerates the development of the national economy.

\section{The Problems Can Be Solved by the Mode of School-enterprise Cooperation Cultivating Postgraduates}

Postgraduates who can achieve national construction and development are the pillars of society. Well-qualified postgraduates are the prominent intellectuals needed by the society. Postgraduate training and education has become the focus of many universities. In recent years, with the constant expansion of graduate education, it's difficult for the colleges and universities to adapt to the requirements of the quality of graduate students in the numbers of the tutor, training funds, laboratory conditions and many other educational 
resources. In addition, because of the restriction of the concepts, systems and many other factors, our national postgraduate education has been confined to the personnel training mode of the "ivory tower" type for a long time. Shortage of teaching resources and single training model have become the bottleneck of the development of Chinese postgraduate education. Economic development and social need make the postgraduates enrollment have expanded each year, but relative lag of school infrastructure leads to the declining quality of graduate education[6]. The kind of whole school education can't make the postgraduates connect the theoretical knowledge with the actual production effectively. When the postgraduates graduate from the school and go to the enterprise, they generally lack the ability of solving the the practical production problems[7]. The mode of schoolenterprise cooperation can solve the problems mentioned above. It's an important way to ensure the quality of postgraduate education by carrying out the research on the innovation system for school-enterprise cooperation cultivating postgraduates and combining with the enterprise. The mode of school-enterprise cooperation has a variety of forms, main three types showed as following $[6,8]$ :

- Schools and enterprises cooperate some projects.This type refers to the specific development project as a bridge of graduate students training in cooperation with the enterprises. Through participating in the project research, the graduate students can improve the research and innovation capacity by using the scientific research resources of schools and enterprises.

- The double tutorial system. This type refers to that the schools and enterprises outfit a tutor for the postgraduates respectively. It can make graduate students have the opportunity to go deep into the enterprises to carry out scientific research activities, which would contribute to reinforcing the practice part of scientific research in postgraduate training.

- Schools and enterprises establish the postgraduate training base. Schools and enterprises set up the research center together. The two sides can apply together for various kinds of research topic. And the postgraduates participate in specific projects and their dissertations can be about some projects.

The mode of school-enterprise cooperation can solve the problems specific as following[9]:
- The school's academic development and academic ranks construction.

- The school's share of the cost of training postgraduates.

- Graduate engineering practice ability and overall quality.

- Enterprising demand for technical and human resource.

- Basic R\&D and innovation capability of the enterprise.

- Converting scientific research to products.

\section{Implementation Conditions}

Shandong University of Technology is a comprehensive university locating in Zibo city of Shandong province. With the development of the society, the school pays more and more attention to the improvement of students' comprehensive quality, especially the postgraduates. The leaders of the school actually connect with many enterprises, and reach an agreement on educating postgraduates together with some of them, including Shandong Lu Yang co., Ltd.

Locating in Yiyuan County, Shandong Province, Shandong Lu Yang Co., Ltd is the first listed company in the ceramic fiber industry. This company attaches great importance to its own R\&D capabilities. And it not only recruits a large number of graduate students, but also cooperates actively with Shandong University of Technology, taking the mode of school-enterprise cooperation to cultivate the talents for the enterprise.

The enterprise technology center of Shandong Lu Yang Co., Ltd was established in 2004 and identified as the state-level enterprise technology center in 2012. Since the technology center is set up, it undertakes two national torch plans, two national key new product plans, nine provincial science and technology plans.And it has not only applied for 84 national patents, but also formulated seven national industry standard and acquired Shandong province science and technology progress prize for 3 times.

Shandong Lu Yang Co., Ltd pays much attention to the communication and cooperation with external research department, and has established the good cooperation with many colleges and universities, including Shandong University of Technology. As a postgraduate of Shandong University of Technology, I have two tutors. One is from the school, and the other is from Shandong Luyang Co., Ltd. They formulate research project together for me. I learn culture 
classes during first-year graduate at school and go to the enterprise to do my research project.

\section{Research and Implementation Content}

The mode of school-enterprise cooperation focus on cultivating the overall quality, comprehensive ability and employment competitiveness of the postgraduates. This mode can cultivate wellqualified and creative talents for different employers by taking the way of combining the classroom teaching with participating in the engineering practice with the different educational environment and resources from the schools and enterprises.

Shandong University of Technology and Shandong Lu Yang Co., Ltd set up a steering committee to jointly agree curriculum system, training plan, training goals and so on. They take the way of the "dual mentoring" to cultivate the postgraduates. Every student has two mentors. One is from the school as the other is from the enterprise. They formulate training programs, select research projects and organize thesis defense. My two tutors formulate the subject "the research and preparation of nano- $\mathrm{SiO}_{2}$ composite insulation materials"for me. Both of them give me a big help in the process of my learning and research. The basic theoretical courses including "Nanometer Materials" and "Refractory Materials" I choose under the guidance of them are closely related to my research subject. These courses enrich my knowledge of theory and make me be able to carry on the deep analysis about the problems that occur during the research of my project. Shandong Lu Yang Co., Ltd provides me with the laboratory and experiment condition. Now I have finished the basic theoretical courses at school in the first year, then I come to the enterprise to carry out my subject. The subject has been basically completed so far. The research and development work named nano microporous insulation board has been effectively transformed into productive forces, which has brought sizable interest to the company. In the next more than half a year I will focus on my these writing. When the co-culture work is finished, the panel of judges composed by the school and enterprise will check and examine my theses.

\section{Conclusion}

The mode of school-enterprise cooperation can make the postgraduates use the resources of the school and the enterprise fully to enrich their theoretical knowledge and improve their practical ability. This kind of mode can make the school use the social resources to educate the postgraduates to meet the need of the enterprise. And it can help the enterprise to make use of the resources of the school to achieve the renewal of the products and technology. In a word, this mode is good for the postgraduates, school and enterprise[9].

\section{References}

[1] Daoquan Luo, "The experience and revelation of cooperative education of foreign colleges and universities," Beijing Education, pp. 62-64, 2007.

[2] Fangliu Chen, "Comparative study and its revelation of industry-university-institute cooperation at home and abroad," Coastal Enterprises and Science \& Technology, pp. 161-165, 2007.

[3] Zhong Li, Ling Xiong and Xiaoping Chen, "Establish grant system and practical teaching bases for full-time professional degree graduate student," Academic Degrees \& Graduate Education, pp. 8-12, 2012.

[4] Jinrong Shen, Zhihua Lin and Ze Tian, "Analysis of the driver mechanism of schoolenterprise joint training graduate students," University Education, pp. 142-144, 2012.

[5] Jiaquan Wang and Yi Tang, "Practice and thinking on school-enterprise joint training graduate students," Popular Science \& Technology, pp. 247-248, 2013.

[6] Zhaojin Wu, "Thinking on the mode of schoolenterprise joint training graduate students," Journal of Anhui University of Technology(School Sciences), pp. 103-105, 2012.

[7] Weigang Zhao, Zhezhe Hou and Shuxia Ren, "Thoughts on cultivating model of postgraduate in university-industry-enterprises cooperative pattern," Journal of Shijiazhuang Tiedao University(Social Science), pp. 86-88, 2012.

[8] Yun Zhang, Jinfang Nie, Jianping Li, Huilin Tao and Fuyou Du, "Some thoughts on the base for joint training of graduate students established by university and corporation," Guangzhou Chemical Industry, pp. 166-167, 2011.

[9] Minjie Zhu, Jianwei Zhang and Shenghua Bao, "Research on the cultivation of logistics engineering application talents by the diversification school-enterprise cooperation," procedia engineering, pp. 4173-4177, 2011. 